\title{
An ECM-ISC based Study on Learners' Continuance Intention toward E-learning
}

\author{
http://dx.doi.org/10.3991/ijet.v10i4.4543 \\ Mingjie Tan ${ }^{1,2}$, Peiji Shao ${ }^{1}$ \\ ${ }^{1}$ University of Electronic Science and Technology of China, Chengdu, P. R. China \\ ${ }^{2}$ Open University of China (Sichuan Branch), Chengdu, P. R. China
}

\begin{abstract}
E-learning has been developing rapidly in recent years; however, as the student number and market scale are growing fast, there is also a growing concern over the issue of high dropout rates in e-learning. High dropout rate not only harms both education institutions and students, but also jeopardises the development of e-learning systems. Understanding the behavioural mechanism of students' continuance learning in online programmes would be helpful for reducing the dropout rate. In order to explain students' continuance intention toward e-learning, this study combines theories from the fields of information management and pedagogy. By adding two constructs, namely academic integration and social integration, from the theories of dropout as antecedent variables, an improved ECM-ISC model for e-learners' continued learning intention was put forward. Results from structural equation modeling (SEM) demonstrate a stronger explanatory power of the new model. Based on the results from empirical analyses, corresponding suggestions are proposed in the end of this paper.
\end{abstract}

Index Terms-E-learning, Continued Learning Intention, ECM-ISC, Structural Equation Modelling

\section{INTRODUCTION}

With the continuous development in communications and information technologies, the e-learning industry has been expanding due to its unique characteristic of being unconstrained by time or geographical limits. According to the Education Factbook published in 2012 by GSV Asset Management, an American education advisory group, the scale of the online learning industry reached US\$90.9 billion in 2012 and was forecasted to grow at a compound annual growth rate of $25 \%$ in the next five years, reaching US\$150 billion in 2017. Existing statistics have shown that the proportion of American higher education students enrolling in at least one online course increased from $9.6 \%$ in 2003 to $33.5 \%$ in 2013 , and the total number of learners is estimated at 710 million [1]. While e-learning has been flourishing, the issue of low student retention rates in has become increasingly prominent. Data from a survey conducted by Duke University showed that the dropout rate of the Massive Open Online Course (MOOC) was up to $90 \%$ [2], and the dropout rate of the Open University, a well-known online education institution in the UK, was up to $78 \%$ [3]. The report on the development of online education in the United States stated that high dropout rate is a primary obstacle for the future growth of online education. Retaining online learners is more difficult than retaining learners in traditional face-to-face education [1]. High dropout rates not only increase the operation costs of education institutions, but are also a waste of time and money that the learners have previously invested. Widespread dropout will harm the future development of the online learning market. Therefore, understanding the mechanisms determining students' decision to continue/discontinue their studies is crucial in taking the necessary steps to reduce dropout rates.

E-learners can be seen as consumers of educational products from education institutions. A few studies have adopted a consumer psychology approach and used students' satisfaction towards online learning to explain students' continuance intention toward e-learning. Other studies have also applied models from the field of information management, such as Technology Acceptance Model (TAM) and Expectation Confirmation Model for Information Systems Continuance (ECM-ISC), to examine students' continuance intention toward e-learning from the perspectives of students' adoption or continuation of e-learning related information systems (IS). Another major line of research uses dropout theories or dropout models in pedagogy to analyse students' dropout behaviour. Given that students of e-learning are different from typical consumers in the market, while the learning information system is only the core part of Eleaning, using a single perspective to explain students' continuance intention is inevitably biased. This study attempts to explain students' continuance intention toward e-learning by treating students' satisfaction as a core factor and ECM-ISC as the theoretical basis, while also introducing two important contructs, namely academic integration and social integration, from pedagogical dropout theories into the analytical model.

Subsequent sections of this article are organized as follows: (1) review of relevant existing theories and research, (2) construction of a conceptual model of continuance intention among e-learners based on the analyses of existing empirical data, (3) explanation of questionnaire design and data collection, (4) testing of the conceptual model using structural equation modelling (SEM), (5)summary and suggestion.

\section{LITERATURE REVIEW}

\section{A. Dropout Theory}

In pedagogy, dropout describes the behaviour where learners discontinue learning. The issue of dropout has been extensively studied by pedagogical scholars. Tinto[4] argues that the congruence of goal commitment and institutional commitment determines learners' dropout 
behaviour. When the two variables are incongruent, dropouts might occur. Goal commitment and institutional commitment change along students' learning process, and these changes are influenced by academic integration and social integration. Academic integration involves learners' academic performances and social integration involves the interaction between a leaner and the learning environment. Based on the concepts above, Tinto proposed a theoretical model of student dropout (Figure 1).

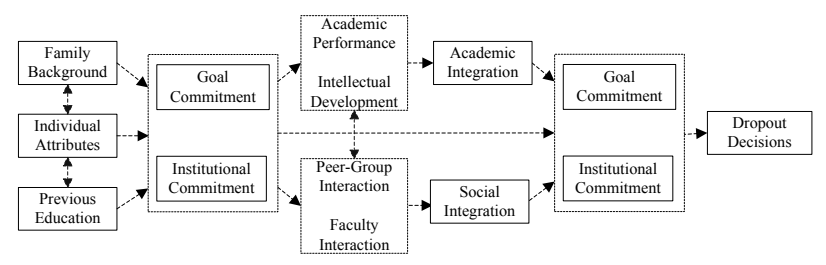

Figure 1. Tinto's Theoretical Model of Dropout

Based on Tinto's theory, Kember elaborated that dropout/continuance decisions of students could be understood as the result of cost-benefit analyses. That is, when the costs are greater than the benefits for continued learning, the student would drop out; or else, the student would continue learning [5]. Rovia pointed out, in an integrated model for explaining continuance decisions in distance learning, that pre-admission personal attributes (i.e. age, ethnicity, and gender), as well as post-admission internal factors (i.e. academic integration and social integration) and external factors (i.e. economic situation, number of working hours, family support, and life crises) would influence students' decisions to continue learning [6]. Therefore, pedagogical research treats academic integration and social integration as important factors to explain the decisions by students to continue (or discontinue) learning. At the same time, there is an emphasis on the concept that students' dropout decisions result from some form of congruence matching or comparison.

\section{B. Theories on the Continued Use of Information Systems}

Adoption of information technology and IS continuance are topics that have interested scholars in the field of information management. Building upon the Theory of Reasoned Action (TRA), Davis proposed a model on information technology acceptance [7]. The model suggests that perceived usefulness and perceived ease of use are two critical factors affecting users' adoption of information technology, and has been often used to explain users' behaviours in the early stages of information technology usage. In contrast, the Expectation Confirmation Model for Information Systems Continuance (ECM-ISC) model proposed by Bhattacherjee focused on understanding users' continuance behaviour during the process of IS usage (Figure 2) [8]. This ECM-ISC model was proposed based on the expectation-confirmation theory and a paradigm of 'expectation - confirmation - satisfaction - intention'. As suggested by this model, a user's initial expectation and degree of confirmation after use will influence their level of satisfaction, while a user's continuance intention depends on their satisfaction towards the IS and its perceived usefulness.

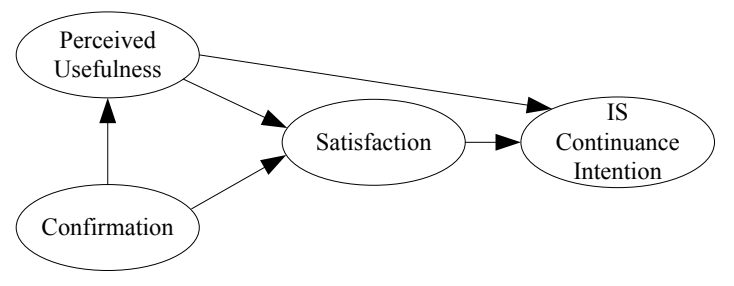

Figure 2. Expectation Confirmation Model for Information Systems Continuance (ECM-ISC)

E-learners use IS, such as learning management systems, to perform learning activities. Hence, to a certain extent, students' continued learning behaviour is equivalent to their behaviour in IS continuance. Following this logic, some scholars have applied ECM-ISC in research on continued learning behaviour in e-learning. Alraimi used ECM-ISC as the foundation of research in order to further examine factors increasing individual learners' continuance intention in MOOC [9]. Empirical analyses showed that aside from the correlation between perceived usefulness and satisfaction, all other original paths in the model were supported. In addition, Chow expanded the existing ECM-ISC by adding four factors of post-adoption expectation (learning process, teachers interaction, peer interaction and course design) between expectation-confirmation and satisfaction. The results showed that the model had a stronger explanatory power on e-learners' continuance behaviour [10].

\section{RESEARCH HYPOTHESES AND CONCEPTUAL MODEL}

To investigate the factors influencing students' elearning continuance and correlations among the factors, this study introduced pedagogical theories to expand the existing ECM-ISC model. According to the ECM-ISC theory, users IS continuance is similar to consumers' repeat consumption in the business world, in that they are both determined by the level of satisfaction [11, 12]. If expectation is confirmed in the early stage of IS use, then the user will be more satisfied and the level of perceived usefulness will also increase. A user's perceived usefulness towards an IS will affect their level of satisfaction and IS continuance intention. The five hypotheses in ECM-ISC have been supported by a large number of empirical studies, for which the research topics have not been limited to e-learning, but have also involved the issues of IS continuance in other areas $[13,14]$. The current study proposes the following five hypotheses according to ECM-ISC:

H1: The higher the student's level of expectationconfirmation toward e-learning, the higher their level of perceived usefulness towards e-learning.

$\mathrm{H} 2$ : The higher the student's level of expectationconfirmation toward e-learning, the higher their expectations toward e-learning.

H3: The higher the student's level of perceived usefulness toward e-learning, the stronger their continuance intention toward e-learning.

H4: The higher the student's level of perceived usefulness toward e-learning, the higher their level of satisfaction toward e-learning.

H5: The higher the student's level of satisfaction toward e-learning, the stronger their continuance intention toward e-learning. 
According to Tinto's dropout theory, academic integration was defined as students' grade performance and intellectual development in the learning process. Grade performance is related to how students fulfil the explicit standards of the education institutions, while intellectual development is related to whether students approve the rules within the academic system. Poor grade performance and difficulty in gaining intellectual development will cause students to feel that they do not fit into the learning environment. Thus, the student would not see the value of learning, often resulting in dropout [4]. As a large proportion of e-learners are part-time learners (with regular jobs), we believe that academic integration should take into account how online learning improves students' vocational skills. Students enroll in online learning with the intention to acquire knowledge and improve their skills. Hence, grade performance and intellectual development would affect a student's level of expectation-confirmation. The above analyses led to the following two hypotheses:

H6: The higher an e-learner's level of academic integration, the higher their level of perceived usefulness.

H7: The higher an e-learner's level of academic integration, the higher their level of expectationconfirmation.

In Tinto's dropout model, social integration was defined as how a student interacts with the learningrelated environment during the learning process. Multiple factors, such as education institutions, teachers, and students, form an academic social system. Likewise, since working students exist within a larger social system, the interactions between their living and work environments with their participation in learning should be included in social integration. Jung et al found in their study that promoting positive interactions between online learners and their learning environment would raise the students' satisfaction level [15]. Baker noted that the relationship between teachers and students would affect how satisfied students are with the school [16]. Based on the above analyses, we propose the following hypothesis:

H8: The higher an e-learner's level of social integration, the higher their level of satisfaction toward e-learning.

By combining the eight research hypotheses proposed above, we propose a conceptual model of learners' continuance intention toward e-learning, which is illustrated in Figure 3.

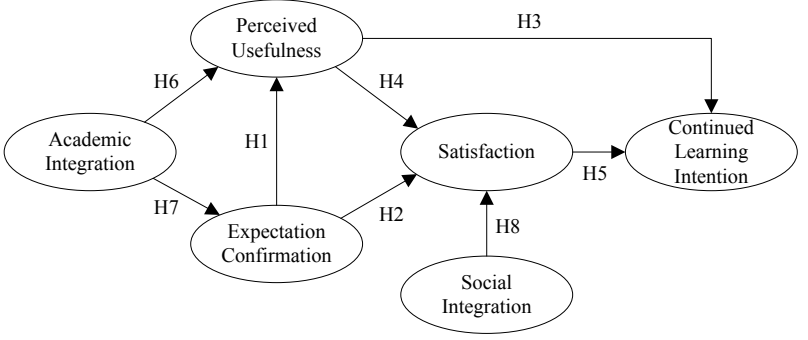

Figure 3. Conceptual Model of E-learners' Continuance Intention toward E-learning

\section{RESEARCH DESIGN}

\section{A. Questionnaire Design and Scale Development}

The questionnaire used in this study is comprised of three parts, personal background information, variable measurement scales and open questions. Personal background information was used to collect data on the participants' basic information, such as age and gender. To ensure the reliability of data and protect the participants' privacy, sensitive information was not gathered in this part of the questionnaire. In the section of open questions, participants were asked about their reasons for continuing (or discontinuing) online learning. Open questions were added to provide additional qualitative analyses along with quantitative analyses.

The measurement scales of the variables were mainly based on existing studies in the area of IS continuance and student dropout, and modified according to the research context and characteristics of online learning. A few of scales were developed by our research group according to the research topic. The measurement scales for academic integration and social integration were established based on Tinto's [4] and Kember's [5] definitions and descriptions of the two concepts, while also referring to Pascarella' s [17] measurement tool. As many online learners were working students, variables measuring the learning characteristics of working students were added to measure the two concepts precisely. The scale on perceived usefulness was created with reference to Davis' [7] and Bhattacherjee's [8] measurement tools. Bhattacherjee's scale on expectation-confirmation was adopted as well as part of the scale on satisfaction level [8]. The scale on continued learning intention was based on Bhattacherjee's scale, but the reverse coding item was removed. The instruments were developed by using fivepoint Likert scale, specifically, 'Strongly Disagree', 'Disagree', 'Neither Agree nor Disagree', 'Agree', and 'Strongly Agree', which were scored from 1 to 5 indicating the degree of agreement.

\section{B. Sample Collection}

The study participants were online learners of the Open University of Sichuan. The Open University of Sichuan is the largest online institution in southwestern China, which has approximately 190,000 students currently enrolled. The questionnaires were distributed online. Aside from the third section for open questions, which was optional, all other questions were compulsory. To improve the response rate, the link to completing the questionnaire was placed at an extremely visible position on the online learning platform. Students had to go through user authentication before filling in the questionnaire, thus improving the reliability of the source of information. Incentives were given to encourage respondents in completing the study; respondents were told that upon the completion of the questionnaire, there was a possibility that they could win some free mobile call credit. This method increased the willingness to participate in the study and the quality of the collected data.

Among the 1,458 collected samples, questionnaires that were completed in very short amount of time or had sequential repetitive answers were excluded; the final number of valid questionnaires was 1,347 . In terms of the demographics of the respondents: for gender distribution, $50.2 \%(\mathrm{~N}=676)$ was male and $49.8 \%(\mathrm{~N}=671)$ was female; for age, $7.2 \%(\mathrm{~N}=97)$ was aged under 20 years old, $47.4 \%$ $(\mathrm{N}=638)$ aged between 21 to 30 years old, 33.9\% $(\mathrm{N}=457)$ aged between $31-40$ years old, $11.1 \%(\mathrm{~N}=150)$ aged between $41-50$ years old, and $0.4 \%(\mathrm{~N}=5)$ aged 50 years old or above. The age and gender distributions were 
consistent with the reported demographics of other published research in the field of online education studies, hence the samples in this study is representative.

\section{DATA ANALYSES AND RESULTS}

\section{A. Reliability Analyses}

Reliability analysis is used to determine the level of reliability of the scales, which includes internal and external reliability. Internal reliability analysis examines whether all items designed to measure the same construct express descriptions with the same meaning. External reliability analysis measures whether a questionnaire yields stable results when it is answered by different people at different times. This study used Cronbach's $\alpha$ to assess the internal reliability of the scales, and $\alpha>0.7$ is considered as an acceptable level of internal consistency
[18]. Results of reliability analyses using SPSS 18.0 are shown in Table 1. Results show that the values of $\alpha$ ranged from 0.746 to 0.934 for individual variables, thus fulfilling the $\alpha>0.7$ requirement, indicating the scales of the questionnaire had relatively high internal reliability. Removal of any of items did not increase the corresponding $\alpha$ of a variable; therefore, no elimination was needed for any of the measured items in the scale. In terms of external reliability, as the majority of the scales used in the present study were based on existing literature, there is relatively high stability. Furthermore, it is difficult and costly to conduct multiple questionnaires among the same study sample pool, thus it was assumed that the scales had a good level of external reliability and no further tests were conducted.

TABLE I.

RELIABILITY AND VALIDITY ANALYSES OF MEASUREMENT SCALES

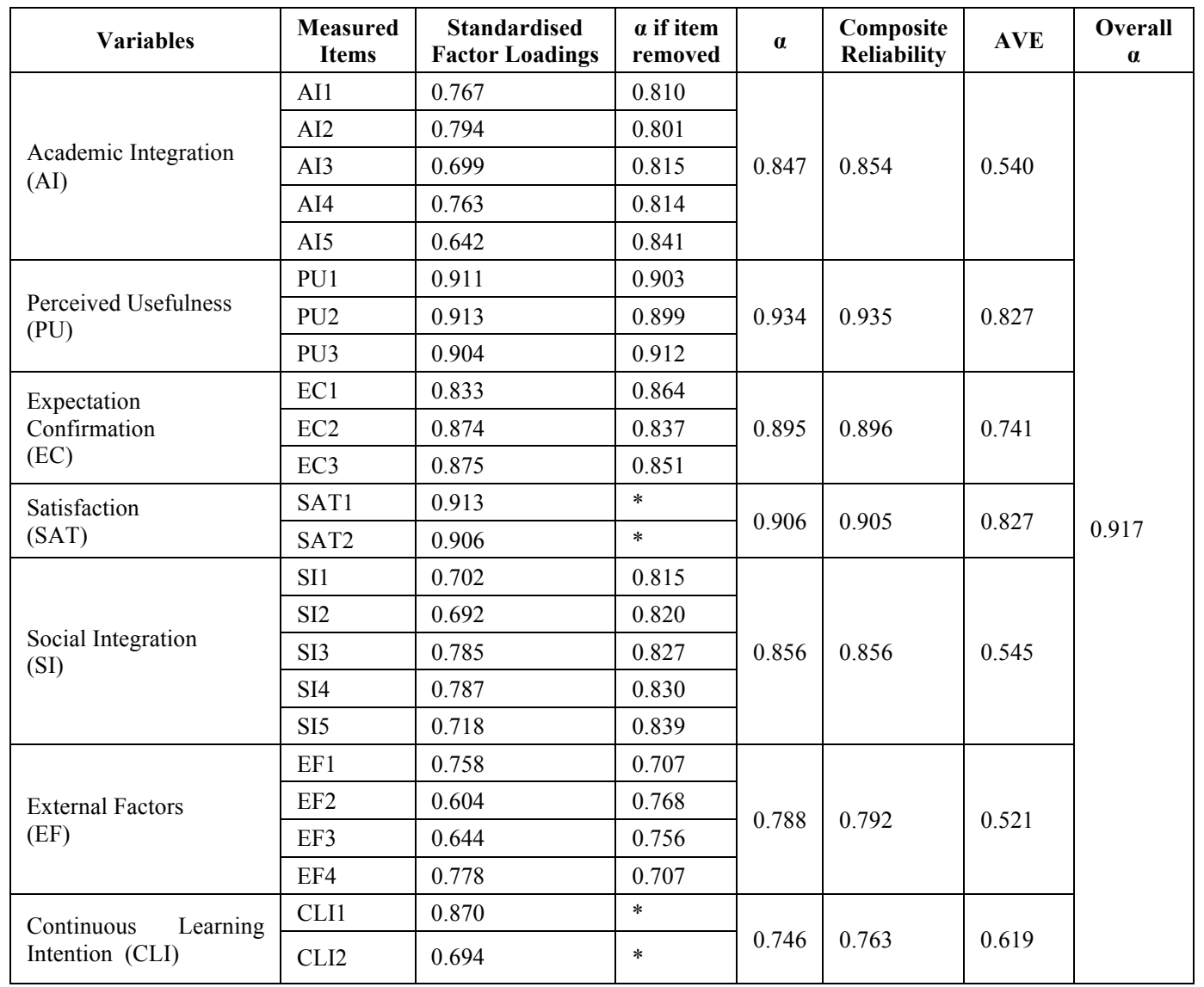

\section{B. Validity Analyses}

Validity refers to the accuracy of the scales, consisting of content validity, criterion validity, and structural validity. Content validity and criterion validity involve the internal logic of a scale. As most of the scales used in this study were based on existing research and were designed after discussions by researchers and managers in the field, it was assumed that the scales had good content and criterion validity. In the following section, the scales were tested on their convergent validity and discriminant validity.
Convergent validity reflects the correlation of different question items within the same concept. Generally, when the standardised factor loading is greater than 0.6 , composite reliability is greater than 0.7 , and average variance extracted (AVE) is greater than 0.5 , it is believed that the internal convergent validity of the model has reached the desired level [18-20]. Analyses and calculations on the initial testing of the measurement model were completed using AMOS 17, and results relevant to convergent validity are presented in Table 3 . All 24 measured items had standardised factor loadings above 0.6, suggesting each measured item had a strong explanatory power for its corresponding latent variable. 
The composite reliability scores of the six latent variables were also above 0.7 (the suggested cut-off value), indicating each group of measured items had high internal consistency. AVE reached the level of 0.5, thus representing the characteristics of the latent variable. In summary, the overall measurement model had a satisfactory convergent validity.

Evaluation of discriminant validity tests whether a measured item only correlates with its corresponding concepts, rather than other concepts. The square root of the AVE of the latent variables and the correlation coefficient between the particular latent variable and other latent variables were compared. If the former is larger, then it indicates that the discriminate validity is better. The test results are shown in Table 2. If the square roots of AVE are larger than the diagonal corresponding correlation coefficient, it means the discriminate validity is good.

\section{Structural Equation Modelling Analyses}

Fit index analyses were conducted using multiple criteria, in which six indices from absolute fit indices, normed fit indices, and parsimonious fit indices, were adopted to evaluate the fit of the model. The criteria and actual results of the selected indexes are presented in Table 3. All fit indexes reached the required cut-off level, indicating a satisfactory fit of the model.
TABLE II.

COMPARISONS OF CORRELATION COEFFICIENT MATRIX AND SQUARE ROOTS OF AVE

\begin{tabular}{|c|c|c|c|c|c|c|}
\hline & AI & SI & PU & EC & SAT & CLI \\
\hline AI & 0.734 & & & & & \\
\hline SI & 0.501 & 0.738 & & & & \\
\hline PU & 0.465 & 0.621 & 0.909 & & & \\
\hline EC & 0.432 & 0.605 & 0.571 & 0.861 & & \\
\hline SAT & 0.547 & 0.620 & 0.593 & 0.601 & 0.909 & \\
\hline CLI & 0.601 & 0.576 & 0.671 & 0.628 & 0.720 & 0.787 \\
\hline
\end{tabular}

TABLE III.

FIT INDEX ANALYSES

\begin{tabular}{|c|c|c|c|c|c|c|}
\hline & $\boldsymbol{\chi} \mathbf{2} / \mathbf{d f}$ & CFI & AGFI & NFI & CFI & RMSEA \\
\hline Fit Criteria & $<5$ & $>0.9$ & $>0.9$ & $>0.9$ & $>0.9$ & $<0.05$ \\
\hline Actual Result & 3.413 & 0.963 & 0.950 & 0.975 & 0.982 & 0.042 \\
\hline
\end{tabular}

In structural equation modelling, standardised path coefficients refer to the correlations between variables. When the $T$ value of the path is greater than 1.96 , the two variables on the path are considered to be correlated. The analyses of the summarised conceptual model are shown in Table 4. All eight hypotheses are confirmed, among which $\mathrm{H} 4$ was statistically significant at the level of $p<0.05$ and the remaining seven hypotheses were statically significant at the level of $p<0.001$.

TABLE IV.

VARIABLES OF SAMPLE ATTRIBUTIONS

\begin{tabular}{|c|c|c|c|}
\hline Research hypotheses & Path coefficient & p-value & Conclusion \\
\hline H1: Perceived usefulness $\leftarrow$ Expectation-confirmation level & 0.208 & $<0.001$ & confirmed \\
\hline $\mathrm{H} 2:$ Satisfaction $\leftarrow$ Expectation-confirmation level & 0.722 & $<0.001$ & confirmed \\
\hline H3: Continued learning intention $\leftarrow$ Perceived usefulness & 0.263 & $<0.001$ & confirmed \\
\hline H4: Satisfaction $\leftarrow$ Perceived usefulness & 0.077 & 0.011 & confirmed \\
\hline H5: Continued learning intention $\leftarrow$ Satisfaction & 0.735 & $<0.001$ & confirmed \\
\hline H6: Perceived usefulness $\leftarrow$ Academic integration & 0.632 & $<0.001$ & confirmed \\
\hline H7: Expectation-confirmation level $\leftarrow$ Academic integration & 0.732 & $<0.001$ & confirmed \\
\hline H8: Satisfaction $\leftarrow$ Social integration & 0.171 & $<0.001$ & confirmed \\
\hline
\end{tabular}

Figure 4 demonstrates the pathways analysis results of the conceptual model, where the pathway coefficients indicate the correlations between the latent variables and $\mathrm{R}^{2}$ represents to what extent a dependent variable can be explained by a corresponding dependent variable. Among the four dependent variables in the model, $\mathrm{R}^{2}$ of both perceived usefulness and expectation-confirmation level was greater than 0.5 and the $\mathrm{R}^{2}$ of both satisfaction and continuous learning intention was greater than 0.8 , thus suggesting a relatively strong power of this model for explaining e-learner's continued learning intention .

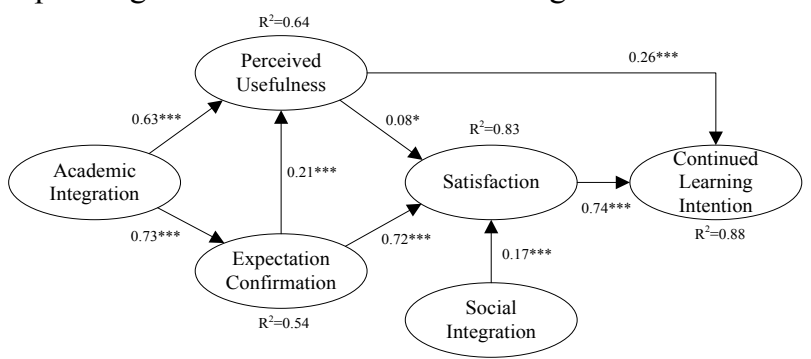

Note: $* * *$ statistically significant at $\mathrm{p}<0.001, *$ statistically significant at $\mathrm{p}<0.05$

Figure 4. Pathways Model and Test Results

\section{CONCLUSIONS AND SUGGESTIONS}

\section{A. Research Conclusions}

Using the theory of information systems continuance as the foundation, this study introduced the two key concepts of academic integration and social integration from dropout theory to investigate e-learners' continued learning intention. The following conclusions can be drawn from the results of empirical analyses.

(1) All original pathways from ECM-ISC model were supported by results of the empirical analyses, suggesting that ECM-ISC is applicable in explaining students' continued learning intention in e-learning. E-learning is based on information technology, and students' attitude towards learning technology will represent their attitude towards learning itself.

(2) As antecedent variables, academic integration and social integration can satisfactorily explain e-learners' perceived usefulness, expectation-confirmation, and satisfaction with e-learning. As the sole antecedent variable, academic integration can explain up to $54 \%$ of 
expectation-confirmation, and $64 \%$ of perceived usefulness. The explanation level of satisfaction is up to $83 \%$, and of continued learning intention is $88 \%$. The results suggest that the improved model, by introducing academic integration and social integration, has a relatively strong explanatory power for e-learners' continued learning intention.

\section{B. Suggestions}

(1) Students' satisfaction of e-learning greatly determines their persistence in completing online learning. Empirical data from this study support the idea that satisfaction affects e-learners' continued learning behaviour, which is consistent with some previous studies $[21,22]$. In order to increase e-learners' satisfaction with online learning programme, it is necessary to understand their needs and provide them with timely learning support.

(2) It is of great significance to pay attention to students' progress in social and academic integration, and offer support services to those who struggle in these two aspects in a timely manner. Considering that e-learners can feel isolated more easily, adding interactive learning and exchange modules are effective means to reduce students' feeling of isolation. In addition, students with poor academic performances should be identified early and be given necessary guidance to improve their academic integration.

\section{REFERENCES}

[1] I. E. Allen and J. Seaman, "Grade change: Tracking online education in the United States," Babson Survey Research Group and Ouahog Research Group, 2014.

[2] L. Perna, A. Ruby, R. Boruch, et al, "The life cycle of a million MOOC users," Presented at the MOOC Research Initiative Conference, 2013

[3] O. Simpson. (2011). 22\%, Can we do better? - the CWP retention literature review final report [Online]. Available: http://www.ormondsimpson.com/index.htm

[4] V. Tinto, "Dropouts from higher education: a theoretical synthesis of the recent literature," Review of Educational Research, vol. 45, pp. 89-125, 1975. http://dx.doi.org/10.3102/00346543045001089

[5] D. Kember, "A longitudinal-process model of dropout from distance education," The Journal of Higher Education, vol. 60, no. 3, pp. 278-301, 1989. http://dx.doi.org/10.2307/1982251

[6] A. P. Rovai, "In search of higher persistence rates in distance education online programs," The Internet and Higher Education, vol. 6, no. 1, pp. 1-16, 2003. http://dx.doi.org/10.1016/S10967516(02)00158-6

[7] F. D. Davis, "Perceived usefulness, perceived ease of use, and user acceptance of information technology," MIS Quarterly, vol. 12, no. 3, pp. 319-340, 1989. http://dx.doi.org/10.2307/249008

[8] A. Bhattacherjee, "Understanding information systems continuance: an expectation-confirmation model," MIS Quarterly, vol. 25, no. 3, pp. 351-370, 2001. http://dx.doi.org/10.2307/3250921

[9] K. M. Alraimi, H. Zo and A. P. Ciganek, "Understanding the MOOCs continuance: The role of openness and reputation," Computers \& Education, vol. 80, pp. 28-38, 2015. http://dx.doi.org/10.1016/j.compedu.2014.08.006

[10] W. S. Chow and S. Shi, "Investigating students' satisfaction and continuance intention toward e-learning: An xxtension of the expectation-confirmation model," Procedia-Social and Behavioral
Sciences, vol. 141, pp. 1145-1149, 2014. http://dx.doi.org/10.1016/j.sbspro.2014.05.193

[11] R. L. Oliver, "Cognitive, affective, and attribute bases of the satisfaction response," Journal of Consumer Research, vol. 20, pp. 418-430, 1993. http://dx.doi.org/10.1086/209358

[12] D. M. Szymanski and D. H. Henard, "Customer satisfaction: a meta-analysis of the empirical evidence," Journal of the Academy of Marketing Science, vol. 19, no. 1, pp. 16-35, 2001. http://dx.doi.org/10.1177/0092070301291002

[13] S. C. Chen, H. H. Chen and M. F. Chen, "Determinants of satisfaction and continuance intention towards self-service technologies," Industrial Management \& Data Systems, vol. 109, no. $9, \quad$ pp. $1248-1263,2009$. http://dx.doi.org/10.1108/02635570911002306

[14] Y. Lee and O. Kwon, "Intimacy, familiarity and continuance intention: An extended expectation-confirmation model in webbased services," Electronic Commerce Research and Applications, vol. $10, \quad$ no. $3, \quad$ pp. 342-357, 2011. http://dx.doi.org/10.1016/j.elerap.2010.11.005

[15] I. Jung, S. Choi, C. Lim, et al, "Effects of different types of interaction on learning achievement, satisfaction and participation in web-based instruction," Innovations in Education and Teaching International, vol. 39, no. 2, pp. 153-162, 2002. http://dx.doi.org/10.1080/14703290252934603

[16] J. A. Baker, "Teacher-student interaction in urban at-risk classrooms: Differential behavior, relationship quality, and student satisfaction with school," The Elementary School Journal, vol. 100, no. 1, pp. 57-70, 1999. http://dx.doi.org/10.1086/461943

[17] E. T. Pascarella and D. W. Chapman, "A multiinstitutional, path analytic validation of Tinto's model of college withdrawal," American Educational Research Journal, vol. 20, no. 1, pp. 87-102, 1983. http://dx.doi.org/10.3102/00028312020001087

[18] R. P. Bagozzi and Y. Yi, "On the evaluation of structural equation models," Journal of the Academy of Marketing Science, vol. 16, no. 1, pp. 74-94, 1988. http://dx.doi.org/10.1007/BF02723327

[19] C. Fornell and D. F. Larcker, "Evaluating structural equation models with unobservable variables and measurement error," Journal of Marketing Research, vol. 18, no. 1, pp. 39-50, 1981. http://dx.doi.org/10.2307/3151312

[20] J. F. Hair, R. L. Tatham, R. E. Anderson, et al, "Multivariate data analysis," Upper Saddle River, NJ: Pearson Prentice Hall, 2006.

[21] M. Herbert, "Staying the course: A study in online student satisfaction and retention," Online Journal of Distance Learning Administration, vol. 9, no. 4, 2006.

[22] O. W. DeShields, A. Kara and E. Kaynak, "Determinants of business student satisfaction and retention in higher education: applying Herzberg's two-factor theory," International Journal of Educational Management, vol. 19, no. 2, pp. 128-139, 2005. http://dx.doi.org/10.1108/09513540510582426

\section{AUTHORS}

Mingjie Tan is with the School of Management and Economics at the University of Electronic Science and Technology of China, No.2006, Xiyuan Ave, West HiTech Zone, 611731, Chengdu, Sichuan, P.R.China. He is also an associate professor of Computer Science at the Open University of China. (e-mail: oliver.tan@163.com).

Peiji Shao is a professor of Information Management at the University of Electronic Science and Technology of China.

Submitted, 20 March 2015. Published as resubmitted by the authors 20 August 2015. 